\title{
A concepção e prática dos gestores egerentes da estratégia de saúde da família
}

\author{
M anagement practice and conception \\ and family health strategy managers
}

M aria I êda Gomes Vanderlei ${ }^{1}$

Maria Cecília Puntel de Almeida ${ }^{2}$

${ }^{1}$ Departamento de Saúde Pública, Universidade Federal do M aranhão. Rua Barão de Itapary 155, Centro. 65020-070 São Luis MA.

iedavanderlei@yahoo.com

${ }^{2}$ Universidade de São

Paulo.
Abstract This paper analyzes municipal management through managerial and manager practices in family health program offices in municipal health ministries and basic health clinics. Theoretically management and social relationship technologies are considered toolsfor thework carried out in the health care field, and they are also valuable instruments for change the micro-policy of the real work done in the health care domain. The methodological approach is qualitative and the research techniques used werethe systematized direct observation as well as semi-structured interviews. The research subjects were the municipal health ministry managers, family health program coordinators and directors from four cities in the state of $M$ aranhão. The results have shown that management is based on a traditional managerial style, characterized by a hard bureaucratic core. However, there is a trend for change be cause in practice, there are already signs which indicate the establishment of accountability and morecaring relationships with respect to usersand their families.

Key words Health services management, Working in health process, Family's health
Resumo Esteestudo analisa a gerência no âmbito munici pal através da prática dos gestores e ge rentes de unidades gestoras de Saúde da Família: secretarias de saúde e unidades básicas de saúde. 0 quadro teórico toma a gerência eas tecnologias de relações sociais en quanto instrumentos do processo de trabalho em saúde, considerando-as ferramentas potentes de mudanças, na micropolítica do trabalho vivo em saúde. A abordagem metodológica é qualitativa e as técnicas de pesquisa foram a observação partici pante sistematizada e as entrevistas semi-estruturadas. Os sujeitos da pesquisa foram os secretários municipais de saúde, coordenadores de Saúde da Família e diretores de quatro municípios do Estado do M aranhão. Os resultados revelam que a gerência está pautada num estilo gerencial tradicional caracterizada por um núcleo burocrático duro, porém com perspectiva de mudança porque, na prática, já existem brechas que sinalizam o estabelecimento de relações de responsabilização e mais acolhedoras com os usuários e as famílias.

Palavras-chave Gerência de serviços de saúde, Processo de trabalho em saúde, Saúde da Família 


\section{Introdução}

0 estudo tem como objetivo analisar a gerência no âmbito municipal através da prática dos gestores e gerentes de unidades gestoras de Saúde da Família: secretarias de saúde e unidades básicas de saúde, de quatro municípios do Estado do Maranhão.

A Estratégia de Saúde da Família - ESF - é apontada como alternativa para reorganização da oferta de serviços de saúde e a proposta insere-se no âmbito do debate em torno das opções para reorientação do modelo assistencial vigente, predominantemente hospitalocêntrico e curativo. A Estratégia de Saúde da Família em certos municípios brasileiros constitui-se em uma estratégia que completa tanto a organização de oferta sobreproblemas enecessidades, aproximando-sedo model o da vigilância à saúde e da distritalização. Por isso, a Estratégia de Saúde da Família atualiza essa figura de modo a inserir-se entre os modelos alternativos ${ }^{1}$.

A principal mudança com a proposta da ESF é no foco de atenção, que deixa de ser centrado exclusivamente no indivíduo e na doença, passando também para o coletivo, sendo a família o espaço privilegiado de atuação. Isso implica em aprendermos a lidar com este novo recorte, tomando agora a família como objeto de trabalho, identificando instrumentos esaberes que possam transformar nossa prática assistencial em direção a uma prática pautada nos princípios éticos e morais e levando a uma maior autonomia dos usuários. No entendimento de Brasil ${ }^{2}$ : Essa perspectiva faz com que a família passe a ser 0 objeto precípuo de atenção, entendida a partir do ambiente onde vive. Mais que uma delimitação geográfica, é nesse espaço que se constroem relações intra e extrafamiliares e onde se desenvolve a luta pela melhoria das condições de vida - permitindo, ainda, uma compreensão ampliada do processo saúde-doença e, portanto, da necessidade de intervenções de maior impacto e significação social.

Assim, a ESF écolocada como uma estratégia desenvolvida para promover mudanças no atual modelo de assistência à saúde do país, possibilitando-se que efetivamente sejam colocados em práticas os princípios que norteiam o SUS, como: integralidade da assistência, universalidade, eqüidade, participação e controle social, intersetorialidade, resolutividade, saúde como direito e humanização do atendimento. E ainda, el ege como ponto central o estabelecimento de vínculos e a criação delaços de compromisso e de co-responsabilidade entre os profissionais. Propõe traba-
Ihar na perspectiva da vigilância à saúde, com responsabilidade integral sobre a população que reside na área de abrangência de suas unidades de saúde².

A conformação da Saúde da Família pelo país afora, mobilizada pela possibilidade do incremento financeiro ao município que se comprometesse com sua implantação, foi determinando, de certa forma, a perspectiva de se colocar gradativamente a Saúde da Família como uma política pública para a reestruturação da atenção básica. Em março de 1996 ( gestão Adib Jatene), por meio de documento preliminar sobre o PSF, aparece certo cuidado com a imagem do programa: não seconstituindo, portanto, em um modelo simplificado, de pobre para pobre, o PSF também não recorta a população em fatias (mulher e criança), nem a atenção em níveis (primário). Integralidade significa também articulação, integração e planejamento unificado de atuação intersetorial. Estasidéias subsidiam o modelo do PSF ${ }^{3}$.

0 ano de 1998 parece ter se constituído um marco para o processo de consolidação do Programa, uma vez que o M inistério o coloca como estratégia estruturante para a organização do sistema de saúde, sendo definido que: Para que o Sistema Ú nico de Saúde funcionasse, o M inistério da Saúde considerava queera necessário sua estruturação numa base municipal sólida equeo mecanismo para isso era a estratégia do PSF organizando a atenção básica. As ações precisavam de fortalecimento para atingir, com qualidade e sustentabilidade, a meta de 150 mil agentes comunitários de saúde e 20 mil equipes de Saúde da Família em atuação no país, atéo fim de $2002^{4}$.

Quando pensamos no tema da gerência, articulada à estratégia do PSF, a tomamos na perspectiva de compreendê-la como um instrumento do processo de trabalho em saúde capaz de contribuir para a transformação deste processo de trabal ho na direção de um modelo assistencial usuário centrado, enão em função do controle e dos procedimentos e, enquanto tecnologia do trabalho em saúde, capaz de ser protagonista de mudanças e com promissada com a defesa da vida do usuário.

Historicamente, a gerência dos serviços de saúde se configurou com um referencial normativo e tradicional que podem ser exemplificado com a caracterização de M ishima5: o conceito do trabalho expõea gerência como uma atividadeextremamente burocrática, no sentido de manipular papéis, sendo um trabalho rotinizado, pré- determinado, com poucas chances de criação, onde se tem intensa padronização e alta dose de inflexibi- 
lidade frente as normas colocadas. Este quadro se contrapõe ao desejo de desenvolver um trabalho maisamplo. 0 perfil quesurge na prática éestritamente burocrático, não sendo a princípio, necessária nenhuma atuação nas questões técnicas ou relacionaisà política de saúde.

Desta forma, concordamos intei ramentecom Campos $^{6}$ quando diz que o pensamento da Administração Científica imprimeum estilo de governar e que seus princípios gerais ainda não foram superados. M esmo que o campo da gestão tenha se ampliado, a disciplina e o controle continuam sendo o eixo central dos métodos de gestão. 0 autor denomina esse eixo conformador do taylorismo de"Racionalidade Gerencial H egemônica": "a estratégia de viabilização do SUS não podese basear centralmentena subordinação dos trabal hadores de saúde por meio de métodos administrativos. Há que se criar uma dinâmica e funcionamento do sistema de tal maneira que os denominados "recursos humanos" seja um dos principais sujeitos do processo de mudança."

No entendimento de Merhy ${ }^{7}$, a gerência utiliza-se das tecnologias leve-duras, das normatizações burocráticas e técnicas para o desenvolvimento do trabalho, e poderia se utilizar, além dessas tecnologias, das consideradas leves - das relações -, o que poderia possibilitar a emergência dos instituintes necessários para a recomposição do trabalho.

0 referido autor classifica as tecnologias de trabalho em saúde em três tipos: tecnologias duras, asinscritas nas máquinas einstrumentos, tecnologias leves, as chamadas tecnologias das relações, do acolhimento e as tecnologias leve-duras são os saberes bem estruturados como, por exemplo, a clínica e a epidemiologia.

Pensando a gerência como potencial detransformação, podemos percebêla como espaço instituinte, com maior participação da equipe dos trabalhadores, ou seja, repensar sua forma de produção e reprodução no que se refere ao gerenciamento dos serviços locais de saúde.

$\mathrm{Na}$ concepção de $\mathrm{Campos}^{8}$, a gerência pode ter esta possibilidade e ainda explicita que: Dentro dessa linha, o gerenteseria mais uma figura que coordena que administra 0 autogoverno, compatibilizando- 0 às diretrizes do planejamento superior que negocia com as outras instâncias do Estado, e da sociedade, eque procura legitimar o trabalho da equipelocal, do queum administrador a la Fayol.

Desta forma, a gerência revela-se a como importante potência de transformação; gestores e gerentes atuando como protagonistas da ação propiciando um arsenal inovador no modo de fazer o gerenciamento da estratégia de saúde da família.

Considerando os princípios do Sistema Único de Saúde-SUS e os objetivos da Estratégia de Saúde da Família-ESF como integralidade e hierarquização, territorialização eadscrição da clientela, equipe multiprofissional, acolhimento, vínculo e a responsabilização, é pensar em uma gerência que se aproprie mais de tecnologias leves e que o primeiro passo para a eficiência gerencial seja a capacidade depossuir uma visão mais dinâmica dos processos organizacionais. É preciso compreender queexistem fatos quenão seenquadram nas regras e determinações organizacionais; portanto, normas são insuficientes para direcionar as organizações. É necessário ter maior sentido de interdependência e lateralidade de pensamento para se compreender a realidade 9 .

No contexto do modelo assistencial proposto pelo SUS e pela ESF, a gerência dos serviços de saúde deveser tomada como um instrumento que pode possibilitar o compartilhar de poder no interior das unidades e equipes de saúde e, neste sentido, poderá se constituir em uma ferramenta importante na efetivação de políticas.

A gerência que se utiliza mais de tecnologias leves - das relações - e considera os profissionais de saúde e os usuários como atores em potencial na produção das ações de saúde, inclusive compreendendo-os como co-responsáveis do trabaIho em saúde, se contrapõe à racionalidade ge rencial burocratizada, normativa e tradicional.

Importantes autores defendem a Gestão Colegiada, na qual a gestão democrática e participativa se constituiu um meio de construção de sistemas de co-gestão e um processo que vem se dando, à medida que se avança na conquista dos "direitos e da cidadania"6,7.

0 repensar do desenvolvimento gerencial, voltado para o modelo assistencial centrado no cuidado, leva a uma redefinição do papel do gerente. Para isso, énecessário à adoção da abordagem dialética para a análise das organizações. M erhy ${ }^{10}$ acrescenta que: a qualificação deum novo modelo assistencial, centrado no usuário ena defesa radical da vida, passa pelo reordenamento das relações entre as tecnologias leves e duras, mediadas pelas leves duras, e considerando que o território das tecnologias leves não é campo espeć́fico de nenhum profissional, mas base para atuação detodos, temos na mediação que os saberes estruturados realizam para incorporar estratégias de intervenções, como no caso de profissões ti pi camente de Saúde, um elemento vital para a ação dos diferentes profissionais de saúde. 
0 estudo parte do pressuposto de que a função gerencial dos gestores egerentes como um dos protagonistas no fazer saúde, a partir da compreensão da Estratégia de Saúde da Família como instrumento de mudança e/ou reorientação do modelo do Sistema Ú nico de Saúde, pode levar à redefinição do papel gerencial centrado nas tecnologias leves - das relações - possibilitando, assim, uma recomposição do trabalho e um agir cotidiano com forca de mudança.

\section{O processo detrabalho em saúde e a gerência}

Para M endes-Gonçalves ${ }^{11}$, o trabal ho é entendido como uma atividadehumana realizada por um grupo de pessoas que a ela se dedica e, assim, reproduz uma existência humana. 0 trabalho é determinado por uma necessidade ou carência, é o meio de subsistência para a satisfação das necessidades materiais e não materiais e também possibilita a livre criação.

0 objeto de trabalho contém o produto, resultante do processo de transformação efetivado pelo trabalho e os meios/instrumentos de trabaIho são constituídos pelo trabalhador que assim estende sua possibilidade de intervenção sobre o objeto ${ }^{12}$.

Dito de outra forma: um objeto de trabalho é um fragmento da realidade recortado por um olhar que concebe, intelectualmente, um produto. A atividade do homem opera uma transformação subordinada a um determinado fim no objeto sobreo qual atua por meio do instrumental detrabalho. Osinstrumentos ou meios de trabalho permitem a aproximação e transformação do objeto; as características do objeto, de um lado, ea finalidade do trabaIho, de outro, determinam as características dos meios de trabalho ${ }^{13}$.

0 trabalho em saúde segueas leis do trabalho em geral; resumidamente, temos o carecimento ou a necessidade individual/coletiva como geradora de uma ação. Esta se desencadeará a partir do estabelecimento de um projeto direcionado para uma finalidade e com o poder de transformação de um objeto de trabalho (fazendo uso de ferramentas - saberes/conhecimento e força de trabalho) que resultará em um produto a ser oferecido para o consumo/utilização, que poderá satisfazer aquele carecimento inicial ${ }^{12}$.

O processo de trabalho em saúde está, como qualquer processo de trabal ho humano, marcado por uma direcionalidade, pressupondo uma antevisão dos resultados e uma ação, que para ser implementada requer uma adaptação constante às características particulares do indivíduo com sua história ${ }^{14}$

0 processo de trabalho em saúdenão podese limitar à polarização entre aqueles que "o produzem" (trabalhadores de saúde) e aqueles que "o consomem" (usuários dos serviços), ten do em vista que se constrói na relação destas pessoas um processo permanente de inter-relação com a sociedade em que vivem, seu modo de produção, seus valores, costumes, sentimentos, razões, que estão em movimento, estão entre luta de opostos, estão se cristalizando e se modificando ao mesmo tempo.

Ao discutir o processo de trabalho, Merhy ${ }^{7}$ apresenta o conceito de trabal ho vivo e trabalho morto. Para uma aproximação a estes conceitos, este autor registra que, para M arx: [...] o trabalho não é compreendido somente em sua dimensão mais operativa enquanto uma atividade, mas, antes de tudo, como uma práxis que expõe a relação homem/mundo em um processo de mútua produção. E, assim, o trabalho "produz" o homem, mesmo que este seja a fonte daquele e que, em potência, de modo virtual, seja o lugar da criação e o momento deexistência eexpressão do trabalho vivo, em atividade.

N este sentido, novos fazeres, novas práticas, se materializam em "tecnologia de trabal ho", usada para produzir saúde. Tecnologia entendida como o conjunto de conhecimentos e ações aplicadas à produção de algo. Este conhecimento pode estar materializado em máquinas e instrumentos, em recursos teóricos e técnicas estruturadas, como tecnologias duras e leve-duras, respectivamente, lugares próprios de trabal ho morto. Por outro lado, este conhecimento pode estar disperso nas experiências e nos modos singulares de cada profissional de saúde bem como na produção de relações tão fundamentais para o trabalho em saúde, queé essencialmente um trabaIho intercessor ${ }^{7}$. Esta função criativa e criadora que pode caracterizar os serviços de saúde, a partir das relações singulares, é operada por tecnologias leves, território onde se inscreve "o trabaIho vivo em ato". Isto só será possível por conquista ou por política institucional, que cada trabalhador utilize o máximo de sua potência para resolver efetivamente os problemas de saúde dos usuários.

De acordo com M erhy', trabalho morto é definido como: [...] a todos aqueles produtos-meios que neles estão envolvidos- ou como fer ramentas ou como matéria prima, como o martelo ea madeira e que são resultados de um trabalho humano ante- 
rior, isto é, não existiam antes da sua produção como resultado deum processo detrabalho, anteriormenterealizado. E os chamamos detrabalho morto neste processo do marceneiro porque, apesar de ser produto de um trabalho vivo, agora ele é incorporado como uma "cristalização" deste trabalho vivo, e de uma maneira distinta do próprio trabal ho vivo em si do marceneiro, que neste momento é o trabalho em ato que permite a produção da cadeira, que, aliás, será um representantea mais do univer so decristalização do trabal ho vivo em morto.

0 trabalho vivo é aquele que se dá em ato, é trabalho em ação, é trabal ho que se realiza utilizando-se de certo saber operante e de determinados instrumentos materiais, com a possibilidade de expressão de criação por parte do trabaIhador. 0 trabalho vivo faz uso do que é dado (trabalho morto) e pode exercer al guma autonomia, sobre esse já dado. [...] no trabalho vivo em saúde, temos trabalho vivo permanentemente trabalho em ato, enele podem estar presentes a finalidade, a antecipação em pensamento e o acionar de processos de criação, satisfazendo necessidades desse próprio homem, que se reconhece nessa forma de trabalho ${ }^{15}$.

É importante destacar que, através da expressão do trabal ho vivo, o trabal hador podeseapropriar dos meios/instrumentos para re-criação do trabalho, desi edos outros, fazendo-se produto e produtor de trabalho.

Entretanto, o trabalho em saúde possui as suas especificidades, tendo em vista que o trabalho vivo não se deixa capturar plenamente, pois não é possível obter estratégias com tal competência, haja vista que" a captura do global do autogoverno nas políticas de saúde não é só muito difícil e restrito, mas impossível pela própria natureza tecnológica desse trabalho"7. Evidenciar esses aspectos édefundamental importância erelevância, pois permite a compreensão do trabalho em saúde como uma prática social que tem finalidades equese definem social ehistoricamente. Utiliza-se de tecnologias diversas, instrumentos e saberes, e toma como objeto de sua ação o homem enquanto sujeito social. Assim, a tecnologia do processo de trabalho em saúde é tomada como um saber eseus desdobramentos em técnicas materiais e não materiais que, ao darem um sentido técnico ao processo, dão-Ihetambém um sentido social.

A atividade gerencial, enquanto parte do processo de trabalho e enquanto instrumento, éconsiderada como uma ação interdisciplinar, ondese fazem presentes determinações de ordem técnica, mas principalmente política, sendo necessária, dentro desta perspectiva, uma compreensão da dinâmica das relações político-econômico-sociais presentes na organização dos serviços de saúde dentro de um dado processo de trabalho ${ }^{5}$.

As considerações feitas por Junqueira e Inojosa ${ }^{16}$ ressaltam que é de suma importância trabalhar-se com a concepção de que o desempenho das atividades geren ciais requer conhecimentos ehabilidades que passam pelas dimen sões técnicas, administrativas, políticas e psicossociais. Essas dimensões possuem significados próprios, permitindo caracterizar não um único estilo de gerência eficaz, mas qualidades que devem permear a ação do gerente.

Para os autores, uma das dimensões importantes na gerência é o comprometimento com a tarefa organizacional e 0 trabalho de envolver todos os recursos humanos nessa tarefa. Fazer com que cada um desempenhe seu papel, mas assuma um compromisso conjunto de produzir um serviço de saúde, que satisfaça às necessidades da população. Corroborando na mesma linha de pensamento Dussault ${ }^{17}$ destaca: É uma gestão que reconhece o papel central dos profissionaise, ao mesmo tempo, tem mecanismos para evitar os efeitos não desejados da autonomia de prática profissional e do corporativismo. Essa gestão enfatiza a definição de mecanismos de tomada de decisões que envolvem os profissionais tanto ao nível da formulação dos objetivos e das orientações gerais quanto da avaliação dos resultados: essa gestão aceita que os profissionais trabalhem não por obedecer à ordem, mas por responsabilidade.

\section{M etodologia}

Trata-se deum estudo de abordagem qualitativa, realizado em quatro municípios do Maranhão: M iranda do Norte, Codó, M orros e São José de Ribamar. Para a seleção dos mesmos, foram identificados todos os municípios do M aranhão que possuíam menos de 20 mil habitantes e cobertura acima de $80 \%$ do Programa Saúde da Família e municípios com mais de 80 mil habitantes e cobertura do Programa Saúde da Família até $50 \%$.

Após, foi feito um sorteio aleatório, definindo-se dois municípios com mais de 80 mil habitantes (Codó e São José de Ribamar) e dois com menos de 20 mil habitantes (M orros e Miranda do N orte). Os sujeitos da pesquisa foram os quatro secretários municipais de saúde, quatro coordenadores do PSF e sete gerentes das unidades de saúde da família, perfazendo um total dequinze trabalhadores de saúde. A coleta de dados se 
deu de setembro de 2003 a fevereiro de 2004, através das técnicas de:

1) O bservação sistematizada do trabal ho, nas quatro unidades de saúde da família selecionadas, através de um guia de observação do processo de trabalho dos gerentes-diretores das Unidades de Saúde da Família onde o pesquisador registrava as atividades real izadas pel os gerentes nos turnos de trabalho. Buscamos captar, observar e registrar a dinâmica da prática gerencial e organização das ações em relação à equipe e aos usuários, contextualizando o observado a partir do marco teórico, para se permitir uma compreensão e uma interpretação da situação observada.

2) Entrevista semi-estruturada com os trabaIhadores de saúde: gestores municipais de saúde, coordenadores do PSF egerentes das unidades de saúde da família. Utilizamos um roteiro contendo questões norteadoras sobreo PSF ea gerência como potencial de transformação do modelo no âmbito municipal.

0 processo de trabalho dos gestores e gerentes no gerenciamento das unidades gestoras - secretarias municipais de saúde e unidades básicas de saúde - é de fundamental importância, tendo em vista que é nos diferentes momentos do processo de trabal ho dos gestores e gerentes de saúde que se capta a realidade de trabalho vivenciada por esses atores e se estabelece uma relação entre o discurso ea prática ese de fato a gerência está sendo tomada ou não como ferramenta de transformação do processo de trabalho na saúde da família.

Todas as entrevistas foram realizadas nas secretarias municipais de saúde e nas unidades de saúde da família, gravadas em fita cassete mediante autorização dos sujeitos, após assinatura do consentimento livre e esclarecido. N ão houve recusa dos profissionais em participar da pesquisa. A pós a transcrição das fitas, foi realizada a leitura "flutuante" das mesmas e em seguida partiuse para a análise de conteúdo temático ${ }^{18}$. Os dados resultantes da observação sistematizada, bem como as falas das entrevistas, foram analisados no seu conjunto. Os dados foram organizados em duas categorias: a) o gerenciamento na saúde da família: como os gestores e gerentes estão fazendo a gestão? b) relações que se estabelecem no cotidiano da prática gerencial.

\section{Resultados/discussão}
a) O gerenciamento na saúde da família: como os gestores e gerentes estão fazendo a gestão?

A gerência se destaca como uma instância de poder. É importantemencionar queindependente da caracterização que o poder possa assumir dentro do setor saúde, este se volta aos propósitos decisórios assumindo possibilidades de promover mudanças e/ou legitimar situações dadas e se compõe como uma ferramenta para impor direcionalidade ao processo de trabalho em saú$\mathrm{de}^{19}$. Nesta direção, apontamos as fal as dos gestores e gerentes demonstrando a prática do gerenciamento na saúde da família:

[...] o meu papel é este: viabilizar o funcionamento das questões técnicas etambém das questões financeiras. E você tem que dar essas condições, de viabilizar desdeo motorista, atéo combustível, não é? (Gestor1).

[...] Eu sempre comparo o gestor de saúde como um maestro, ele tem várias pessoas que el etem que orquestrar, não é?Fazendo a sintonia. Se o gestor não tem o conhecimento do que éa estratégia saúde da família enem a importância dessa estratégia para que haja um melhoramento da saúde, émuito difícil a saúde da família dar certo. (Gestor 4).

[...] Veja bem, se o coordenador não tivesse à frente, quais as decisões que seriam tomadas? Porque eu tenho diretamente 0 acesso para falar com meu secretário. E tenho a liberdade de fazer quando não consigo falar com ele. Dar carta branca para o coordenador. E o que seria dele sem o coordenador? Eu sou uma mão, para o meu secretário. (Coordenador 1).

[...] Ele é imprescindível, ele é o comando. Ele que comanda, ele que tem a palavra final, não é? As idéias partem na grande maioria de quem está na ponta - que são os técnicos. Eles vêm até os gestores pra fazer estudo, levantamento, vê as condições da própria secretaria no que se refere a recursos humanos, materiais e financeiros. Então, o papel do gestor está praticamente nisso aí, oferecer as condições necessárias pra que se desenvolva o trabalho. (Coordenador 4).

Tomando em particular a fala do Gestor 4, a gerência implica uma função integrativa do ponto de vista das relações no trabalho e também possibilita perceber suas relações com o trabaIho em equipe, ou seja, tomar a gerência como uma atividade indispensável à administração do desempenho humano coletivo, por isso seria comparada à função desempenhada pelo maes- 
tro ao comandar a orquestra. Entretanto, a fala do G estor 1 se encaminha mais para uma prática gerencial voltada para o cumprimento de metas, provedor de materiais e em função dos problemas detectados.

$\mathrm{Na}$ observação sistematizada do trabalho, verificamos que existeum pool deatividades voltadas para a organização do processo de trabaIho, infra-estrutura e planejamento de serviços (ações administrativas) executados pelos gerentes das unidades de saúde da família.

Entre elas, destacam-se: supervisionar a limpeza, providenciar reparo e manutenção de material, planejar, coordenar esupervisionar os serviços de saúde, prever material permanente, distribuir tarefas, enviar relatórios, dentre outras. Acrescidas a essas atividades, verificou-se: a) atividades deorganização do fluxo, como por exemplo: enfermeira gerente chega à microárea do povoado e organiza a fila de dispensação de medicamentos; $b$ ) atividades voltadas para a comunicação: enfermeira gerente entrega cartazes de al eitamento materno para o ACS para a divulgação da semana na sua área adscrita; enfermeira gerentefala sobrea preparação de um fôlder para o curso das gestantes, campanha do exame preventivo e do registro civil (situações resultantes das observações de campo da UnidadeA2) .

$\mathrm{Na}$ prática gerencial dos diretores das UBS, foram observadas várias atividades voltadas para a tomada de decisões, assim como instrumentos de comunicação e de informação direcionados à organização e ao funcionamento dos serviços de saúde. Dessa forma, entre as atividades gerenciais direcionadas para as decisões, destacou-se:

- Reuniões de trabalho: enfermeira gerente coordena reunião no hospital com as outras enfermeiras e vacinadoras sobre a descentralização dos exames das DST /AIDS e das vacinas de rotina; - enfermei ras gerentes partici pam da reunião no hospital com as outras enfermeiras e vacinadoras sobre a descentralização dos exames das DST/AIDS e das vacinas de rotina; - enfermeira gerente faz reunião com os ACS sobre diversos assuntos, a saber: a ausência das mulheres para fazer o exame preventivo, a campanha da dengue, o planejamento familiar a produtividade de cada agente, discutindo os problemas de cadaárea (situações resultantes das observações de campo das Unidades A1 eA2).

- Atividades gerenciais direcionadas ao funcionamento da UBS: enfermeira gerente decide dispensar a ACS que viera ajudar na UBS e fica só, pois a outra auxiliar de enfermagem estava de folga; enfermeira gerente decide marcar as con- sultas só pela manhã para os turnos matutino e vespertino; gerente avisa a auxiliar de enfermagem para vir na segunda-feira pela manhã para a marcação de consultas (situações resultantes das observações de campo das Unidades A2 e B3).

Deum modo geral, as atividades voltadas para a tomada de decisões se configuram como ações administrativas centradas na pessoa do gerente, em que as relações de poder são mais centralizadas, caminhando muito mais para um estilo de gerência tradicional, isto é, uma racionalidade gerencial hegemônica que produz um isolamento e dificulta a construção de espaços onde ocorra o desenvolvimento da personalidade humana, ou seja, (um lugar onde se produziria aprendendo e, também, ao mesmo tempo, se reconstruiria a própria subjetividade) ${ }^{6}$.

Kliksberg ${ }^{20}$ aponta queo gerente público precisa ser capaz de incentivar e dar espaço à criatividade individual e de criar condições para que, através da coletivização de idéias, ela setransforme em inovações e práticas diferenciadas.

Todas as narrativas retratam o agir e o pensamento gerencial desses agentes do trabalho/trabal hadores de saúde sustentados numa visão ordenada e tradicional da gerência na qual o dirigente deve ser um decisor racional, e pensar a realidade administrativa como racional controlável e possível de ser uniformizada.

b) Relações que se estabelecem

no cotidiano da prática gerencial

A prática gerencial como uma ferramenta importante detransformação do processo detrabalho deveter como um dosinstrumentos a construção de relações entre as pessoas, onde a comunicação entre os profissionais, por exemplo, passa a ser um determinador comum do trabaIho em equipe, o qual decorre da relação recíproca entre trabalho e interação. A gerência, no diaa-dia das unidades básicas de saúde, comporta esses vários tipos de relações, o que vai configurar o tipo de gestão e o papel dos dirigentes enquanto gestor e/ou gerente dos serviços de saúde. $\mathrm{Na}$ fala da entrevistada foi explicitado "um agir democrático":

[...] as decisões são tomadas assim: eu repito, já falei anteriormente, eu gosto muito de agir democraticamente, eu não gosto denada quevem de cima para baixo, também eu não mando nada de cima para baixo, não imponho nada... N ós nos reunimos, eu já digo o que é necessário fazer, o que eu quero quefaça, eu entre aspas, não é? 0 quea uni- 
dade precisa que seja feito... e também ouço opiniões (Gerente A3).

Entretanto, na observação de campo na unidade $\mathrm{A} 3$ com a mesma gerentenuma conversa que ela estabelece com os agentes comunitários de saúde, verificamos momentos contraditórios entre o discurso (fala) e a prática gerencial:

(...) eu vou fazer reunião hoje á tarde, as ACS perguntam: não pode ser amanhã, porque fica difícil a gente avisar as outras; porém a enfermeira gerente responde: não, tem que ser hoje mesmo! (O bservação de campo na unidade A3).

As relações são partes constitutivas do processo de trabalho e são matéria prima para compreender como está se dando a gerência, haja vista que nela se processam as relações de poder compartilhado, relativo, parcial, autoritário e departamentalizado. 0 tipo das relações encaminha para uma gestão participativa, democrática ou, pelo contrário, autoritária ou centralizadora. Nesse sentido, ressaltamos que as relações de poder estabelecidas entre os gerentes coordenadores do PSF e os diretores das UBS, no que se refere às decisões no âmbito do gerenciamento na saúde da família, estão mais para o poder autoritário ou o departamentalizado.

[...] as decisões são tomadas assim: eu procuro falar com o coordenador do PSF, ele resolve os problemas. Ás vezes tem problemas na unidade. 0 que éda unidade eu resolvo, mas quando é do PSF éo coordenador do PSF que resolve (Gerente B).

[...] as deci sões... Bom, aí nesse caso fica lá com a equipe, não é? Eles decidem e passam para o coordenador eeles lá deliberam, dentro do queé possível. Eu sou informada e então eu fico sabendo. [...] com relação ao PSF, eleusa a estrutura da unidade mas eu acompanho a freqüência dos profissionais, se a demanda é grande ou pequena, 0 atendimento, ou seja, sou ol heira do PSF (GerenteB3).

[...] À proporção que vai acontecendo um problema ou se tem uma informação nova, eu encaminho para o secretário ou para o coordenador do PSF para tirar alguma dúvida ou para saber como devo proceder no dia-a-dia (Enfermeira gerente A2).

Analisando as falas dos gerentes, observamos duas situações: o coordenador do PSF só é acionado em função de uma informação nova ou é "quem decide", ou seja, o gerentenão tem nenhuma autonomia no gerenciamento do PSF. Em outros momentos da observação de campo, verificamos que a relação de poder não difere das mencionadas nas falas dos entrevistados:

[...] Eu não posso abrir mão porque senão vira bagunça.. Nesse momento, entra 0 coordenador do
PSF e fala: "não deve mesmo" e a mãe da criança sai reclamando eentão a diretora nos ol ha ediz: "eu cumpro ordem aqui, o sistema de funcionamento é assim" (Situação resultante da observação de campo - Fala do coordenador do PSF eda gerenteB3).

$A$ autonomia responsável é necessária para 0 trabal ho gerencial, tendo em vista que o gerente representa no nível local a consecução das diretrizes políticas de saúde colocadas para as UBS.

Sendo assim, retomamos $\mathrm{Campos}^{6}$, que resume o papel da direção em múltiplas dimensões: uma voltada para a gestão de modelos de atenção (modos de organizar os processos de trabaIho objetivando a produção de valores de uso); outra especial mente concentrada em administrar pessoal (construção de equipes com autonomia e responsabilidade); outra ainda, mais tradicional, de administração financeira e centrada na sobrevivência da organização; e, por fim, uma última de representação política nos sistemas públicos, governos e sociedade em geral.

A gerência em saúde é uma atividade meio, cuja ação central está posta na articulação e integração, e que, ao mesmo tempo em que possibilita a transformação do processo de trabalho, é também possível de transformação mediante as determinações que se fazem presentes no cotidiano das organizações de saúde, ou seja, que se transforma diante da finalidade colocada para o trabalho.

Neste contexto, cabe à gerência um caráter articulador eintegrativo, ou seja, a ação gerencial é determinada pelo e determinante do processo de organização de serviços de saúde e fundamental na efetivação de políticas sociais, em especial, as de saúde. No entanto, em algumas situações, os escassos recursos de ordem organizacional, material, cognitiva e, até mesmo ética, fazem com que o trabalho da gerência se reduza a controlar e executar tarefas destinadas a alcançar o produto e o impacto esperado.

Ao visualizarmos a gerência como uma ferramenta importante do processo de trabalho e considerando os princípios do SUS e do PSF que apontam possibilidades de mudança, por exemplo, a Saúde da Família, concebida pelo M inisté rio da Saúde como uma estratégia para a mudança do modelo assistencial², percebemos brechas para constituir um trabalho diferente, ondeo vínculo, a escuta, a responsabilização e as distintas formas de acolher o usuário são vistas como instrumentos para esse trabalho.

Assim, neste momento, trazemos algumasfalas e situações que sinalizam esses momentos de encontro dos gerentes com os usuários: 
[...] gerente conversou com a gestante que faltava atender porque o carro chegou para buscá-la, mas antes ela perguntou para a gestante: você pode ficar no povoado atéa tarde? E a gestante respondeu quesim. (Situação resultanteda observação de campo - fala da Gerente A2).

[...] dona fulana (nomeda usuária): o carro do PSF passa no sábado na hora que vier do município (nomedo município) para apanhá-la para uma consulta na uni dade porquea sua pressão está alta. E a senhora respondeu: Eu já combinei com dona cicrana (nomeda vizinha) quevamos assistir a festa de São Francisco (padroeiro do povoado). A enfermeira gerente diz: não tem problema, pois a consulta na unidadeé só pela manhã e depois da consulta à senhora e sua vizinha pode ir à festa, não se preocupe que 0 carro tem vaga para as duas. $\mathrm{E}$ a ACS fala: passem lá em casa para tomar um café" (Situação resultante da observação de campo - fala da GerenteA2 e da ACS).

As atitudes das gerentes trazem explicitamente essa perspectiva de mudar o jeito de atender e de se relacionar com o trabalho da Saúde da Família, ou seja, estabelecimento do vínculo com os usuários, que representa uma ferramenta importante para a produção do cuidado que representa trabal ho vivo. Matumoto ${ }^{21}$ diz que: [... ] a proximidade com as famílias e aqui acrescentamos a relação com os usuários vai possibilitando estabelecer brechas no trabalho para a criação de uma relação diferente daquela presente nos serviços de saúde: fugaz, despersonalizada, centrada no recorte específico da queixa, da doença. (Grifo nosso)

A relação dos gerentes com os usuários evidenciada nas falas e ações caracterizam o uso de tecnologias leves que possi bilitam o trabal ho vivo em ato.

Esses depoimentos conduzem a pensar e reforçar as afirmações de Merhy ${ }^{7,22}$, quando 0 autor faz a distinção de trabalho vivo e trabalho morto, já referido anteriormente, e afirma que 0 trabalho vivo se faz presente com certa sabedoria, em saber ser e assim operar a produção de determinados produtos típicos destetrabalhador.

N essa perspectiva, ou seja, na Gestão Compartilhada, a gerência éum instrumento potente para operar mudanças nas práticas de saúde direcionadas para 0 acolhimento e cuidado, tendo como foco principal o usuário e a família.

Passo $^{23}$, referindo-se à citação de Fracolli e Egry, diz que o processo de trabal ho de gerência em UBS e- acrescentamos - na Saúde da Família envolve um duplo movimento: deum lado, a execução de práticas gerenciais que tomam como seu campo de ação o território de formulação e deci- são política e, de outro lado, o território de práticas gerenciais que enfrentam o fabricar "bens" do trabal ho em saúde. 0 que condiz com o ponto de vista de Merhy $^{7}$ que o processo de trabalho de gerência em uma U BS torna-se o lugar de possíveis intervenções impactantes sobre a política e o modelo de aten ção a saúde.

Dessa forma, a gerência passa a ser uma ferramenta do processo de trabalho em saúde, possibilitando transformações nas decisões no âmbito local com a participação do trabalhador de saúde e do usuário na construção do projeto assistencial a ser desenvolvido pelo serviço da saúde $E$, sendo assim, o gerente eficaz não é aquele que domina apenas as técnicas de gestão, mas o que possui compromisso como tarefa organizacional eécapaz demobilizar o conjunto da organização para essa tarefa, de forma criativa e participativa.

\section{Considerações finais}

M ediante as observações das atividades realizadas pelos diretores das UBS e de acordo com a fala dos gestores e gerentes municipais, verificamos que a gerência está centrada na lógica tradicional, o quese constitui o núcleo duro da gerência, isto é, as tecnologias duras em que se emprega muito tempo e se desperdiça muita energia, onde estão evidenciadas as ações burocráticas, ou seja, o trabalho morto e a lógica taylorista - normatizada e burocrática.

Associa-se a isso um conjunto muito mais complexo, onde estão presentes as relações instituídas entre gestores e gerentes, relações de poder centralizado e onde as formas de controle superam a flexibilização e a autonomia responsável dos trabal hadores, demonstrando o quanto ainda é hegemônico o pensamento da gerência clássica e que, na maioria das vezes, a gerência ainda se caracteriza com um grande centro de "poder e burocracia".

$\mathrm{Na}$ prática gerencial dos gestores e gerentes (coordenadores do PSF ediretores das UBS), evidenciamos a ausência de autonomia responsável para quetome decisões no gerenciamento do PSF. Isso compromete em muito a prática gerencial desses gerentes, uma vez que a autonomia é necessária para a definição de ações prioritárias para a assistência à saúde no âmbito da área de abrangência das UBS.

Entretanto, mesmo com essa realidade onde a gerência aparece para legitimar situações dadas ao invés de ser uma ferramenta para promover 
mudanças, não podemos deixar de destacar alguns avanços, uma vez que na prática dos gerentes já existem al gumas situações que sinalizam o estabelecimento dessas relações mais acolhedoras com os usuários e com a família. Essas são, portanto, as brechas que se abre com a Saúde da Família tendo em vista os seus princípios, assim como os espaços intercessores que se estabelecem no campo das relações dos gerentes com os usuários que representam, sobretudo, o uso de tecnologias leves e que é trabalho vivo.

Diantedisso, acredita-senuma prática gerencial assentada nas tecnologias leves, o que possibilitará situar o gerente da estratégia da saúde da família para o cuidado da família.

Verificou-seque existeperspectiva de mudança no gerenciamento da saúde da família, na medida em que se encaminha para uma gestão compartilhada e que o gerente tem um papel importante nessa gestão participativa. Por isso, no seu cotidiano deverão ser instituídos encontros entre gestores, gerentes, trabalhadores de saúde, equipe do PSF e usuários, de modo que esses encontros se constituam em espaços de análise, to- mada de decisão e implementação de tarefas. Dessa forma, concordamos inteiramente com Campos ${ }^{6}$ quando coloca que: [... ] cabe aos dirigentes, particularmentena área de serviços, cuidar dos padrões éticos e de responsabilização dos trabal hadores diante de suas clientelas. Descentrar 0 foco da gestão, retirando-o da gestão de coisas, ou de tarefas, ou de procedimentos, centrando-o em administrar relações interpessoais e os resultados dessas relações.

Concluindo, dizemos que o papel dos gestores e gerentes na gestão compartilhada passa a ser um dispositivo importante, uma vez que agindo dessa maneira estaria rompendo com a racionalidade gerencial hegemônica e fazendo uso do aspecto positivo do poder descentralizado, envolvendo toda a equipe da saúde da família para um projeto assistencial coletivo e conseqüentemente mudando a prática atual de produzir saúde. Apostando assim, numa gerência que possa utilizar-se das tecnologias leves - das relações - o que poderia possibilitar uma recomposição do trabalho e imprimir mudanças no modo de fazer saúde.

\section{Colaboradores}

MIG Vanderlei, MCP de Almeida participaram igualmente de todas as etapas da elaboração do artigo. 
Referências

1. Oliveira MS. A academia apostando na estratégia da Saúde da Família. Rev. Bras. Saúde da Família 2000; (3): $46-52$

2. Brasil. M inistério da Saúde. Saúde da família: uma estratégia para a reorganização do modelo assistencial. Brasília: M inistério da Saúde; 1998.

3. Vasconcellos M PC. Reflexões sobre a saúde da família. In: Mendes EV, organizador. A organização da saúde no nível local. São Paulo: Hucitec; 1998. p.155-172.

4. Brasil. Ministério da Saúde. Departamento de Atenção Básica. Relatório de Gestão 1998 -2002. Brasília: Ministério da Saúde; 2002.

5. MishimaSM. Constituição do gerenciamento local na rede básica de saúde de Ribeirão Preto [tese]. Ribeirão Preto (SP): Escola de Enfermagem de Ribeirão Preto; 1995.

6. Campos GWS. Um método para análise e co-gestão de coletivos. São Paulo: Hucitec; 2000.

7. Merhy EE. Em busca do tempo perdido: a micropolítica do trabalho vivo em saúde. In: M erhy EE, Onocko $\mathrm{R}$, organizadores. Agir em saúde: um desafio para 0 público. São Paulo: Hucitec, Lugar Editorial; 1997.

8. Campos GWS. Reforma da reforma: repensando a saúde. São Paulo; Hucitec; 1992.

9. M otta PR. Gestão contemporânea: a ciência e a arte de ser dirigente. Rio de Janeiro: Record; 1999.

10. Merhy EE. A gestão do cotidiano em saúde e 0 ato de governar as tensões constitutivas do seu agir: desafio permanente das estratégias gerenciais adotadas. Campinas: 1998. [M imeo].

11. M endes-Gonçalves RB. Tecnologias e organização social das práticas de saúde: características tecnológicas de processo de trabalho na rede estadual de centros de saúde de São Paulo. São Paulo: Hucitec; 1994.

12. M endes-Gonçalves RB. Práticas de saúde: processos de trabalho e necessidades. Cad. CEFOR 1992.

13. Rocha SM M. O processo de trabalho em saúde e a enfermagem pediátrica: sociedade e historicidade [tese]. São Paulo (SP): Escola de Enfermagem da Universidade de São Paulo; 1990.
14. Fracolli LA. Processo de trabalho de gerência: possibilidades elimites frenteà reorganização do trabal ho na rede básica de saúde em M arília [tese]. São Paulo (SP): Escola de Enfermagem da Universidade de São Paulo; 1999.

15. Fortuna CM . 0 trabalho de equipenuma unidade básica de saúde: produzindo e reproduzindo-se em subjetividades e em busca do desejo, do devir e de singularidades [dissertação]. Ribeirão Preto (SP): Escola de Enfermagem de Ribeirão Preto, Universidade de São PauIo, 1999.

16. Junqueira L, Inojosa RM. Gestão dos serviços públicos de saúde: em busca de uma lógica da eficiência. Revista Administração Pública 1992; 26 (2):20-31.

17. Dussault GA. Gestão dos serviços públicos de saúde: características e exigências. Revista de Administração Pública 1992; 26 (2):8-19.

18. M inayo M C. 0 desafio do conhecimento: pesquisa qualitativa em saúde. São Paulo: Hucitec-Abrasco; 2000.

19. Bertussi DC, Mishima SM . 0 desenvolvimento gerencial como intervenção estruturante da atenção básica de saúde. In: V Congresso Nacional da Rede Unida; I Congresso Nacional de Redes em Saúde; I M ostra Parnaense de Saude da Família; 2003; Londrina, Paraná. p. 1-18. [Relatório final da Oficina de Trabalho].

20. Kliksberg B. A gerência na década de 90 . Revista Administração Pública 1988; 22 (1): 59- 85.

21. M atumoto S. 0 acolhimento: um estudo sobre seus componentes e sua produção em uma unidade básica de saúde [dissertação]. Ribeirão Preto (SP): Escola de Enfermagem de Ribeirão Preto; 1998.

22. M erhy EE. Saúde a cartografia do trabalho vivo. São Paulo: Hucitec; 2002.

23. Passos JP. A utilização de indicadores na prática gerencial do enfermeiro em unidades básicas de saúde [tese]. São Paulo (SP): Escola de Enfermagem de São Paulo; 2004.

Artigo apresentado em 28/02/2005

Aprovado em 26/06/2006

Versão final apresentada em 09/10/2006 